Revista Brasileira de Agricultura Irrigada v.12, nº.3, p. 2673 - 2682, 2018

ISSN 1982-7679 (On-line)

Fortaleza, CE, INOVAGRI - http://www.inovagri.org.br

DOI: $10.7127 /$ rbai.v12n300851

Protocolo 851.18 - 22/12/2017 Aprovado em 11/06/2018

\title{
DENSIDADE DO SOLO E RESISTÊNCIA MECÂNICA À PENETRAÇÃO DE CAMBISSOLOS EM AGROECOSSISTEMAS NO SEMIÁRIDO POTIGUAR
}

\author{
Yally Ayaky Dantas Fernandes ${ }^{1}$, Marisa Taís de Oliveira Silva ${ }^{2}$, Jeane Cruz Portela ${ }^{3}$, \\ Phamella Kalline Pereira Farias ${ }^{4}$, Sandy Thomaz dos Santos ${ }^{5}$, Joaquim Emanuel Fernandes \\ Gondim $^{6}$
}

\section{RESUMO}

A densidade do solo e a resistência mecânica à penetração (RP) influenciam o espaço poroso, interferindo diretamente no crescimento e produção agrícola das culturas. O objetivo do trabalho foi avaliar atributos estruturais de solos em agroecossistemas no semiárido, tendo a área de mata nativa preservada como referência e adotando como impeditivo ao crescimento das raízes o valor crítico de RP igual a $2 \mathrm{MPa}$. O estudo foi desenvolvido no projeto de Assentamento Terra da Esperança, no município de Governador Dix-Sept Rosado - RN, nos seguintes agroecossistemas: área de mata nativa preservada (AMNP), área de preparo intensivo (API), área de cultivo de cajueiro (ACCaju), Área coletiva de mata nativa (ACMN) e área agroecológica (AAG), coletando-se amostras nas camadas 0,00-0,10 m e 0,10-0,20 m, com estruturas deformadas e indeformadas para avaliação da densidade do solo (Ds), densidade das partículas (Dp), porosidade total (Pt) umidade gravimétrica (Ug) e a RP em campo, esta última com trinta leituras para cada agroecossistema supracitado. Os solos foram classificados como Cambissolo, com exceção da ACCaju, um Latossolo. A AMNP apresentou os maiores teores da fração argila em ambas as camadas e o maior valor de RP, com 1,56 MPA, explicada pela superfície consolidada e predominância da fração argila. ACCaju apresentou os menores valores da fração argila e maiores da fração areia, resultando assim em maiores valores de Ds. Já os valores da Dp foram próximos e a Ug foi considerada baixa. Os diferentes manejos adotados nos agroecossistemas não resultaram em impedimento ao crescimento das raízes.

Palavras-Chaves: estrutura, assentamento rural, compacidade.

\section{SOIL DENSITY AND MECHANICAL RESISTANCE TO THE PENETRATION OF CAMBISSOLOS IN AGROECOSYSTEMS IN THE SEMIARID POTIGUAR}

\footnotetext{
${ }^{1}$ Graduando em Agronomia, UFERSA, Mossoró, e-mail: yallyayaky@hotmail.com

2 Engenheira Agrônoma, UFERSA, Mossoró, e-mail:marisa_tais@hotmail.com

${ }^{3}$ Doutora em Ciência do Solo, Prof. ${ }^{a}$ UFERSA, jeaneportela@ufersa.edu.br

${ }^{4}$ Doutoranda em Manejo de Solo e Água, UFERSA, Mossoró, email:phamellakalliny@hotmail.com

${ }^{5}$ Mestrando em Manejo de Solo e Água, UFERSA, Mossoró, email: Sandy_thomaz@hotmail.com

${ }^{6}$ Mestrando em Ciência do solo, UFPB, Areia, email:joaquimcg_rn@hotmail.com
} 


\begin{abstract}
Soil density and mechanical resistance to penetration (PR) influence pore space, directly interfering with crop growth and productivity. The objective of this study was to evaluate the structural attributes of soils in agroecosystems in the semi - arid region. The native forest area was preserved as a reference and the critical value of RP equal to $2 \mathrm{MPa}$ was used as an impediment to root growth. The study was developed in the Land of Hope Settlement project, in the municipality of Governor Dix-Sept Rosado - RN, in the following agroecosystems: preserved native forest area (AFNP), intensive preparation area (API), area of cashew (ACashew), collective forest area (ACF) and agroecological area (AAG). Samples were collected in the layers $0.00-0.10 \mathrm{~m}$ and $0.10-0.20 \mathrm{~m}$, with deformed and undeformed structures for density evaluation (Ds), particle density (Dp), total porosity (Pt), gravimetric humidity (Ug) and field PR, the latter with thirty readings for each agroecosystem mentioned above. The soils were classified as Cambisols, with the exception of ACashew, an Oxisol. The AFNP presented the highest levels of the clay fraction in both layers and the highest value of PR, with 1.56 MPA, explained by the consolidated surface and predominance of the clay fraction. ACashew presented the lowest values of the clay fraction and higher of the sand fraction, resulting in higher values of Ds. Dp values were close and Ug was considered low. The different management practices adopted in agroecosystems did not result in an impediment to root growth.
\end{abstract}

Keywords: structure, rural settlement, compactness.

\section{INTRODUÇÃO}

Nos solos de usos agrícolas se faz necessário um ambiente propício ao desenvolvimento das culturas, pois ele é o responsável pela transmissão de nutrientes, água, ar e calor às sementes e plantas. O sistema agrícola deve contribuir para a manutenção ou melhoria da qualidade do solo e do ambiente, bem como para a obtenção de produtividade satisfatória das culturas no longo prazo (COSTA et al., 2003).

Entretanto, o manejo inadequado pode ocasionar degradação e perda da qualidade do solo e causar prejuízo para a sua sustentabilidade, sobretudo quando se trata da qualidade física. Brady e Weil (2013) dizem que a qualidade do solo é a capacidade do solo em realizar suas funções ecológicas, como meio para crescimento das plantas, regulador do abastecimento de água, reciclador de matériasprimas, agente modificador da atmosfera, habitat para seus organismos e como meio para obras de engenharia.

Sabendo-se disso e que as condições químicas e físicas são alteradas a partir do momento em que o solo se torna de uso agrícola, faz-se crucial o controle dessa degradação (TORMENA, 2002; MOME FILHO, 2012), buscando “práticas de manejo que mantenham ou melhorem as condições estruturais dos solos” (ROMERO, 2007). Essas práticas devem ser mais intensas e adequadas para que os solos das terras agrícolas tenham melhor qualidade, como um recurso pra suportar todos os ecossistemas (BRADY; WEIL, 2013).

Com isso, o principal efeito dessas alterações é o processo de compactação, pois quando forças compactativas são aplicadas ao solo, ocorre um rearranjamento das partículas, proporcionando maior contato entre elas, modificando a estrutura da camada arável, posteriormente o encrostamento superficial ou compactação em camadas mais profundas denominadas pé-de-grade ou pé-de-arado (GABRIEL FILHO et al., 2000), observado pelo aumento da densidade e resistência mecânica à penetração (LIMA et al., 2007).

Esta ocorrência implica na baixa infiltração, o que reduz o armazenamento de água no solo; déficit no crescimento radicular, afetando consideravelmente a capacidade de absorção de água e, consequentemente de 


\section{DENSIDADE DO SOLO E RESISTÊNCIA MECÂNICA À PENETRAÇÃO DE CAMBISSOLOS EM AGROECOSSISTEMAS NO SEMIÁRIDO POTIGUAR}

nutrientes e redução da porosidade total, além do tamanho e da continuidade dos poros (DEXTER, 2004), consequentemente, o aumento do escoamento superficial com perda de matéria orgânica e redução da produtividade, já que o crescimento vegetal varia de forma inversamente proporcional a essas propriedades.

Em decorrência da fragilidade e diversidade dos solos, junto a não observância das particularidades locais, a compactação do solo é um dos graves problemas enfrentado pelos produtores rurais do Semiárido Potiguar (COSTA et al., 2015).

Dessa forma, as propriedades físicas mais importantes para o manejo e estudo da qualidade física dos solos é a sua resistência mecânica à penetração e a densidade do solo (STONE et al., 2002), as quais funcionam como indicadores do grau de compactação, principalmente, de possível impedimento ao crescimento radicular.

A resistência à penetração serve para descrever a resistência física que o solo oferece a algo que tenta se mover através dele (SILVEIRA et al., 2010). Um dos equipamentos para sua determinação é o penetrômetro (MOME, 2012), que “compõe-se de uma haste metálica com extremidade cônica, que é introduzida no solo por movimento contínuo ou por impactos" (REICHARDT; TIMM, 2012).
A densidade do solo é uma propriedade física de fácil mensuração e de baixo custo, por isso é bastante usual para determinação da qualidade física de solos agrícolas, conseguindo quantificar o estado poroso do solo apercebendo as mudanças em seu volume (SILVA, 2011).

Diante do exposto, o presente trabalho teve o objetivo de avaliar a qualidade física de Cambissolos em agroecossistemas no Semiárido Potiguar, por meio da densidade do solo e resistência mecânica à penetração de raízes.

\section{MATERIAL E MÉTODOS}

As áreas estudadas estão compreendidas no Projeto de Assentamento (PA) Terra da Esperança, localizado no município de Governador Dix-Sept Rosado, com distanciamento de doze quilômetros do centro da cidade, possuindo área total de 6.297 hectares divididos em uma vila com 113 famílias entre as coordenadas $05^{\circ} 27^{\prime} 32,4$ " de latitude Sul e 37³1'15,6” de longitude Oeste, no Estado do Rio Grande do Norte, na mesorregião Oeste Potiguar e microrregião da Chapada do Apodi, inseridas no Semiárido do Brasil (Figura 1).

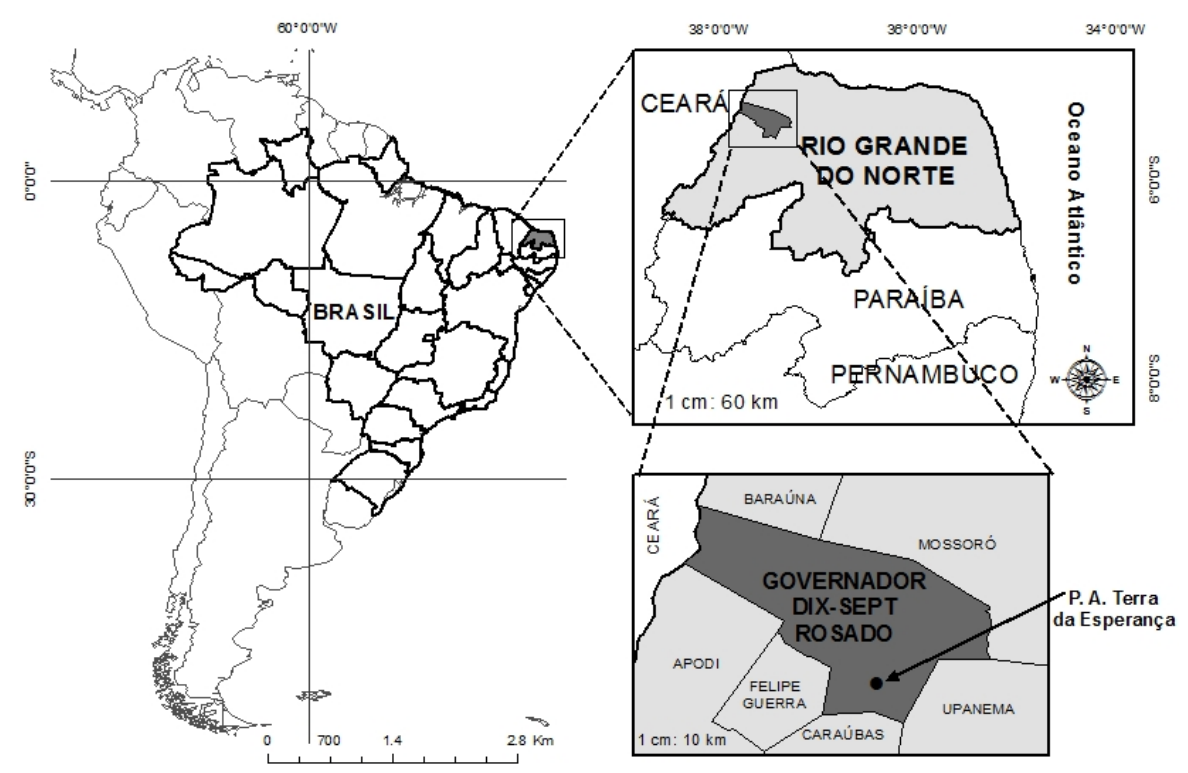


Figura 1. Localização da área de estudo Localização da área de estudo: Projeto de Assentamento Terra da Esperança no Município, Estado e País.

O município de Governador Dix-Sept Rosado apresenta classificação climática segundo Köppen, de semiárido quente com duas estações distintas, seca e chuva, com precipitação pluvial média anual de $712 \mathrm{~mm}$ durante os meses de fevereiro a maio, temperatura média anual de $27^{\circ} \mathrm{C}$ e umidade relativa média do ar de $68,9 \%$. A sua vegetação nativa é a Caatinga Hiperxerófila (SOUZA, 2014).

A pesquisa foi realizada em cinco agroecossistemas com características peculiares: área de mata nativa preservada (AMNP); área de preparo intensivo (API); área de cultivo de cajueiro (ACCaju); área coletiva de mata nativa (ACMN) e área agroecológica (AAG). Vale ressaltar, que todas as áreas estudadas tiveram como base um (01) ha na coleta de amostras de solos. Os solos foram classificados como Cambissolo para as respectivas áreas: mata nativa preservada (AMNP); preparo intensivo (API); coletiva de mata nativa (ACMN) e agroecológica (AAG), com exceção da área de cultivo de cajueiro (ACCaju) que foi classificado como Latossolo.

A área de mata nativa preservada (AMNP), sendo a mesma considerada como referência, tendo como predominância espécies vegetais da Caatinga hiperxerófila, com exemplares: mofumbo (Combretum leprosum L.), aroreira (Schinusterebinthifolius), marmeleiro (Cydonia oblonga Mill) e juremapreta (Mimosa hostilis Benth).

Área de preparo intensivo (API), usada para plantios consorciados, não possuindo um sistema de irrigação, sendo cultivada somente do período chuvoso. No momento da pesquisa a área encontrava-se em pousio, devido ao período seco prolongado com consequente exposição à radiação solar ao longo de sua superfície.

Área de cultivo de cajueiro (ACCaju), composta anteriormente por uma maior variedade de espécies da Caatinga hiperxerófila, mas devido ao plantio de cajueiros, encontrou-se desmatada e em estágio final de produção.

A área coletiva de mata nativa (ACMN) é amplamente utilizada pelos agricultores para extração de lenha.

A área agroecológica (AAG) que tem como principal propósito a produção de alimentos (frutíferas e forrageiras) para sustento das famílias e dos animais. As áreas supracitadas foram georeferenciadas (Tabela1).

Tabela 1. Coordenadas dos locais amostrados, Governador Dix-Sept Rosado

\begin{tabular}{ccc}
\hline Agrossistemas & Latitude & Longitude \\
\hline Área de mata nativa preservada (AMNP) & $05^{\circ} 29^{\prime} 13.2^{\prime \prime} \mathrm{S}$ & $37^{\circ} 24^{\prime} 23.1^{\prime \prime} \mathrm{W}$ \\
Área de preparo intensivo (API) & $05^{\circ} 30^{\prime} 15.8^{\prime \prime} \mathrm{S}$ & $37^{\circ} 27^{\prime} 02.4^{\prime \prime} \mathrm{W}$ \\
Área de cultivo de cajueiro (ACCaju) & $05^{\circ} 29^{\prime} 42.8^{\prime \prime} \mathrm{S}$ & $37^{\circ} 28^{\prime} 30.4^{\prime \prime} \mathrm{W}$ \\
Área coletiva de mata nativa (ACMN) & $05^{\circ} 30^{\prime} 17.6^{\prime \prime} \mathrm{S}$ & $37^{\circ} 27^{\prime} 1.3^{\prime \prime} \mathrm{W}$ \\
Área agroecológica (AAG) & $05^{\circ} 29^{\prime} 13^{\prime \prime} \mathrm{S}$ & $37^{\circ} 24^{\prime} 33.1^{\prime \prime} \mathrm{W}$ \\
\hline
\end{tabular}

Para realização das análises laboratoriais foram coletadas cinco amostras compostas deformadas, oriundas de quinze subamostras, em quatro pontos nas áreas supracitadas. A coleta foi feita com auxílio de um trado tipo holandês, executada em ziguezague. As camadas utilizadas foram: $0,00-0,10 \mathrm{~m}$ e 0,10 $0,20 \mathrm{~m}$. As amostras foram colocadas em sacos plásticos, identificadas e conduzidas para o
Laboratório de Análise de Solo Água e Planta LASAP/UFERSA. Em seguida as amostras foram secas ao ar, destorroadas e peneiradas em malha de 2,0 mm, obtendo assim a porção de terra fina seca ao ar (TFSA), para realizar a análise granulométrica e densidade de partículas.

A determinação da granulometria foi obtida pelo método da pipeta utilizando-se 


\section{AGROECOSSISTEMAS NO SEMIÁRIDO POTIGUAR}

dispersante químico (Hexametafosfato de sódio) e água destilada em 20 g da TFSA, com agitação mecânica lenta em agitador (Wagner $50 \mathrm{rpm}$ ) durante 16 horas (TEIXEIRA et al., 2017). A areia (2 a $0,05 \mathrm{~mm}$ ) foi mensurada por tamisagem, a argila $(<0,002 \mathrm{~mm})$ por sedimentação e o silte $(0,05$ a $0,002 \mathrm{~mm})$ por diferença entre as frações de areia e argila.

A avaliação da densidade de partículas foi executada pelo método do balão volumétrico, utilizando-se terra fina seca em estufa (TFSE) a $105^{\circ} \mathrm{C}$ e álcool etílico (TEIXEIRA et al., 2017).

Ainda dentro de cada área estudada, foram coletadas cinco amostras indeformadas de solo, nas camadas de $0,00-0,10$ e $0,10-0,20$ $\mathrm{m}$, fazendo-se uso anéis volumétricos com dimensões de $0,05 \mathrm{~m}$ de altura e $0,05 \mathrm{~m}$ de diâmetro e tomando-se a média aritmética de cinco repetições por camada, tornou-se possível a determinação da densidade, sendo representada pelo quociente da massa das partículas sólidas do solo pelo volume total do solo.

Disponíveis os valores das densidades, foi possível a determinação da porosidade total.

A resistência mecânica à penetração de raízes (RP) foi determinada nas condições de campo, utilizando um penetrômetro de impacto da VDO $^{\circledR}$ (modelo SS316), com ponteira de 1,386 cm de diâmetro, área de secção transversal de $1,509 \mathrm{~cm}^{2}$ e ponta cônica com ângulo de penetração de $30^{\circ}$, onde a ponta cônica e a haste do equipamento eram inseridas no solo por meio da força física do usuário. As leituras foram realizadas na camada superficial $(0,00-0,10 \mathrm{~m})$ com 30 repetições feitas de maneira aleatória em cada área supracitada, obtendo assim os valores médios de RP. Os resultados foram expressos em $\mathrm{MPa}$. Na mesma ocasião coletou-se amostras de solos com estruturas deformadas nas camadas $0,00-0,10 \mathrm{e}$ 0,10-0,20 m, para avaliação da umidade gravimétrica.

Os dados foram submetidos à análise de variância (ANAVA) e as médias foram analisadas e comparadas por meio do Teste de Tukey em nível de 5\% de probabilidade, para cada agroecossistema, utilizando o programa estatístico ASSISTAT 7.6 ${ }^{\circledR}$.

\section{RESULTADOS E DISCUSSÃO}

Verificou-se variação na classe textural nas áreas em estudo (Tabela 2). As áreas que apresentaram textura franco argilo arenosa em sua superfície $(0,00-0,10 \mathrm{~m})$ foram: área de mata nativa preservada (AMNP), Área de preparo intensivo (API), área coletiva de mata nativa $(\mathrm{ACMN})$ e área agroecológica (AAG), porém na camada seguinte $(0,10-0,20 \mathrm{~m})$ a AMNP passou a ser classificada como argila e API como argilo arenosa, fato ocorrido devido ao aumento da fração argila. 
Tabela 2. Distribuição do tamanho das partículas, classificação textural, densidade de solo, densidade de partículas, umidade do solo e porosidade total das áreas em estudo do Projeto de Assentamento Terra de Esperança, Governador Dix-Sept Rosado - RN nas camadas 0,0-0,10 e 0,10-0,20

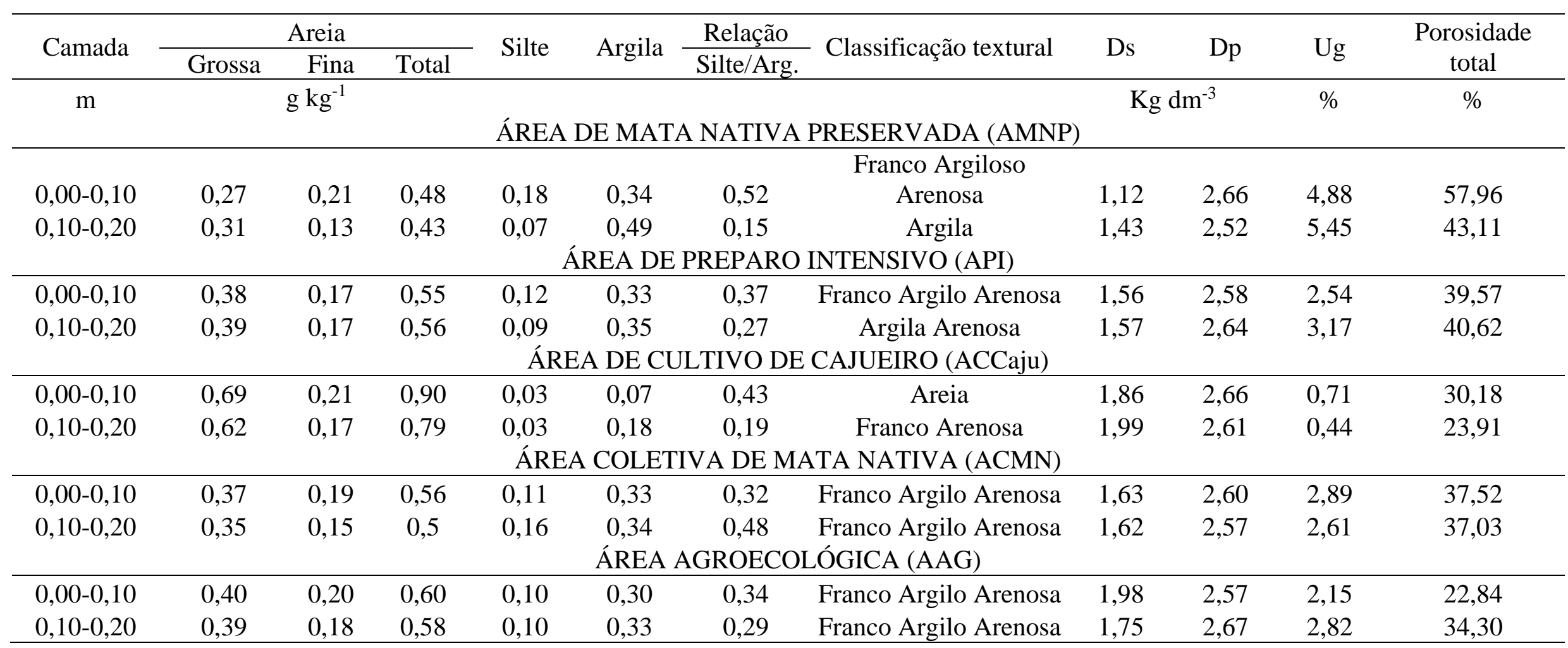




\section{DENSIDADE DO SOLO E RESISTÊNCIA MECÂNICA À PENETRAÇÃO DE CAMBISSOLOS EM AGROECOSSISTEMAS NO SEMIÁRIDO POTIGUAR}

Marinho et al. (2016) ao estudar atributos físicos em Cambissolos sob agroecossistemas áreas de mata nativa e preparo convencional também encontrou mesma predominância de classificação textural franco argilo arenosa em superfície e argilosa em subsuperfície.

A ACMN e AAG permaneceram com a mesma classificação textural em ambas as camadas estudadas, fato explicado pela preservação da área no decorrer dos anos, já que não houve práticas de preparo do solo.

A área de cultivo de cajueiro (ACCaju) foi a única com textura arenosa em sua superfície $(0,00-0,10 \mathrm{~m})$ e franco arenosa em subsuperfície $(0,10-0,20 \mathrm{~m})$. Essa distinção da fração areia está provavelmente ligada a litologia, pois seu material de origem é o arenito, e por pertencer a classe dos Latossolos. O Latossolo encontra-se no local mais alto da paisagem. "Na Chapada do Apodi, têm se uma sequência de calcários margosos e calcários homogêneos (puro, litográfico e detrítico) e com intercalações de arenito calcífero no topo" (FERREIRA, 2013), onde o intemperismo químico é intenso, tendo boas características quanto à drenagem, pois o perfil apresenta uma boa profundidade efetiva, e limitações químicas, pois quem define a fertilidade do solo é a fração argila, e no solo em questão essa fração é reduzida.

Comparando a área de mata nativa preservada (AMNP) com a área de preparo intensivo (API), verificou-se um decréscimo da fração argila e silte nas camadas avaliadas (Tabela 2), sendo mais expressiva a perda da fração argila na subsuperfície, onde passou de 0,49 $\mathrm{g} \mathrm{kg}^{-1}$ na AMNP para 0,35 $\mathrm{g} \mathrm{kg}^{-1}$ na API, motivados pelo preparo intensivo $\mathrm{e}$ revolvimento do solo, ocorrendo uma mistura de material, quebrando os agregados e deixando-os expostos, ocasionando a perda de partículas finas pelo vento.

Erosão, iluviação e intemperismo dos minerais, agindo por muito tempo tendem a provocar mudanças na textura de certos horizontes de um solo. No entanto as práticas de manejo não modificam a textura do solo; nesse caso, as mudanças em um determinado material de solo poderiam ocorrer pela adição ou mistura de um material de solo com outro de textura distinta (BRADY; WEIL, 2013).

Os maiores valores de densidade do solo (Ds) (Tabela 2), foram observados na ACCaju, explicado pela elevada quantidade da fração areia total em função do material de origem arenito. Marcolin \& Klein (2011) corrobora a informação, segundo o mesmo a densidade do solo apresentam grande amplitude, e variam conforme textura, mineralogia, matéria orgânica bem como práticas de manejo, sendo a densidade dos solos arenosos superiores aos dos solos argilosos.

A maior amplitude de variação da densidade de partículas foi observada na AMNP (Tabela 2), com intervalos de 2,52 kg $\mathrm{dm}^{-3}$ em sua subsuperfície até 2,66 $\mathrm{kg} \mathrm{dm}^{-3} \mathrm{em}$ sua superfície, essa pouca variação é explicada pela sua mineralogia. A Dp é uma característica que não depende do tamanho ou arranjo das partículas do solo (estrutura do solo), e sim da parte sólida, (inorgânico e orgânico), ou melhor, a matriz do solo (KIEHL, 1979).

Os valores da umidade gravimétrica (Ug) não mostraram diferenças expressivas entre as camadas de cada agroecossistema (Tabela 2), porém apresentaram maiores diferenças entre os agroecossistemas em estudo. Os teores da Ug no solo são considerados baixos, possivelmente em razão da ausência de chuvas por um longo período, sendo exibidos os intervalos de umidade: $\mathrm{Ug}=0,44 \%$ na área de ACCaju, explicado pela textura arenosa, que se aquece mais facilmente, e tem uma drenagem mais rápida (BRADY; WEIL, 2013) e Ug $=5,45 \%$ $(0,10-0,20 \mathrm{~m})$ na AMNP em razão da cobertura, da maior quantidade da fração argila e sua capacidade de retenção de água, por seu arranjo estrutural, tendo assim maior percentagem de microporos. Solos argilosos apresentam porosidade total variável com predomínio de microporos, proporcionando assim uma boa retenção de água (UNTERLEITNER, 2011). Jakelaitis et al. (2008) avaliando a qualidade do solo em agroecossistemas verificou que a área de mata nativa obteve maior valor de umidade gravimétrica $(\mathrm{U}=0.18 \quad \mathrm{~kg} . \mathrm{kg})$ quando comparado a outros agroecossistemas (áreas de pastagem e área cultivada). 
Os dados de resistência mecânica do solo à penetração (RP) foram resultados da média de um total de trinta (30) repetições na superfície $(0,00$ - 0,10 m) de cada agroecossistema (Tabela 3). Verificou-se variação significativa entre os valores médios de RP, sendo o maior valor na área de mata nativa preservada, medindo 1,49 MPa em função da consolidação da superfície, como também do aumento da fração argila, com predominância de microporos, diferindo estatisticamente dos demais agroecossistemas.

Tabela 3. Resistência mecânica à penetração em cinco agroecossistemas distintos, Governador DixSept Rosado- RN

\begin{tabular}{cc}
\hline Agroecossistemas & RP \\
\hline & Mpa \\
Área de mata nativa preservada (AMNP) & $1,49 \mathrm{~b}$ \\
Área de preparo intensivo (API) & $1,07 \mathrm{a}$ \\
Área de cultivo de Cajueiro (ACCaju) & $1,15 \mathrm{a}$ \\
Área coletiva de mata nativa (ACMN) & $1,06 \mathrm{a}$ \\
Área agroecológica (AAG) & $1,02 \mathrm{a}$ \\
\hline $\mathrm{CV}(\%)=24,63$ & \\
\hline
\end{tabular}

Em virtude da maior microporosidade, solos argilosos podem apresentar maior porosidade total, promovida pelo maior teor de argila (MIOTTI et al., 2013), conforme a Tabela 2, onde o valor encontrado da porosidade total $(\mathrm{Pt})$ foi de $57,96 \%$, sendo superior aos demais agroecossistemas.

O baixo valor de RP encontrado na API foi devido ao fato dela ter passado por preparo intensivo com uma aração e duas gradagens, no momento da avaliação o solo estava exposto e susceptível à degradação, com ausência de plantas espontâneas. Esse preparo intenso provocou um aumento provisório da porosidade do solo, elevando assim a porosidade total momentânea. $\mathrm{O}$ arado promove o revolvimento da superfície do solo, e em seguida a grade faz o nivelamento da superfície quebrando os agregados, facilitando a perda do material pelo vento. O revolvimento do solo com arado e grade diminui a densidade e a capacidade de campo, em contrapartida, aumenta a porosidade total, a macroporosidade e a capacidade de aeração (MIOTTI et al., 2013).

Na área coletiva de mata nativa (ACMN) o valor de RP foi de 1,06, pois apesar da consolidação da sua superfície, não causou restrição e manteve sua qualidade estrutural.

Os valores de RP (Tabela 3) não foram considerados impeditivos ao crescimento das raízes, pois não chegaram a $2 \mathrm{MPa}$, resultados semelhantes aos apresentados em Costa et al. (2015) e Souza (2014).

Os resultados da análise de variância da $\mathrm{RP}$ indicam que houve diferenças significativas entre os tratamentos (Tabela 3).

Em relação ao dado de coeficiente de variação obtido no estudo (Tabela 3), apresentando valor médio de acordo com Gomes (2000), pode ser justificado pela influência dos agroecossistemas supracitados, com características peculiares às particularidades locais.

\section{CONCLUSÕES}

A área de mata nativa preservada apresentou maior resistência à penetração de raízes, em função da consolidação da superfície do solo.

A textura do solo, em especial a fração areia total, contribuiu para o aumento da densidade do solo na área de cultivo de Cajueiro (ACCaju).

A área com preparo intensivo do solo (API) ocasionou degradação estrutural, reduzindo á resistência mecânica à penetração inicial e a densidade do solo.

As práticas de manejo do solo e dos cultivos agrícolas adotadas nos agroecossistemas estudados, de maneira geral, 
não resultaram em condições restritivas ao crescimento vegetal quanto à resistência à penetração de raízes e a densidade do solo.

\section{REFERÊNCIAS BIBLIOGRÁFICAS}

BRADY, N.; WEIL, R. Elementos da natureza e propriedades do solo. 3.ed. Santana: Bookman, 2013. 685p.

COSTA, F. S.; ALBUQUERQUE, J. A.; BAYER, C.; FONTOURA, S. M. V.; WOBETO, C. Propriedades físicas de um Latossolo Bruno afetadas pelos sistemas plantio direto e preparo convencional. Revista Brasileira de Ciência do Solo, v.27, p.527535, 2003. http://dx.doi.org/10.1590/S010006832003000300014.

COSTA, J. D.; PORTELA, J. C.; SILVA, E. F.; MARINHO, A. C. S.; JÚNIOR, F. S. S.; FERREIRA, D. A. C Densidade do solo e resistência à penetração em um Cambissolo sob diferentes usos agrícolas. In: CONGRESSO BRASILEIRO DE CIÊNCIA DO SOLO, 35., Natal. Anais... Natal: CBCS, 2015. p.1-4. http://eventosolos.org.br/cbcs2015/arearestrita/ arquivos/716.pdf

DEXTER, A. R. Soil physical quality. Part I. Theory, effects of soil texture, density, and organic matter, and effects on root growth. Geoderma, n.120, p.201-214, 2004. https:// doi:10.1016/j.geoderma.2003.09.005

FERREIRA, E. P. Gênese e Classificação de Solos em Ambiente Cárstico na Chapada do Apodi. 2013. 107f. Dissertação (Mestrado Curso de Agronomia), Universidade Federal Rural do Rio de Janeiro, Seropédica.

GABRIEL FILHO, A.; PESSOA, A. C. S.; STROHHAECKER, L.; HELMICH, J. J. Preparo convencional e cultivo mínimo do solo na cultura de mandioca em condições de adubação verde com ervilhaca e aveia preta. Revista Ciência Rural, v.30, n.6, p. 953-957, 2000. http://dx.doi.org/10.1590/S010384782000000600005.
GOMES, F. P. Curso de estatística experimental. $14^{\mathrm{a}}$ ed. Piracicaba, São Paulo, Degaspari, 2000. 477p.

JAKELAITIS, A.; SILVA, A. A.; SANTOS, J. B.; VIVIAN, R. Qualidade da camada superficial de solo sob mata, pastagens e áreas cultivadas. Pesquisa agropecuária tropical, v.38, n.02, p. 118-127, 2008. https://www.revistas.ufg.br/pat/article/view/41 71/3665.

KIEHL, E. J. Manual de edafologia: relações solo-planta. São Paulo: Ceres. 1979. 262p.

LIMA, C. G. R.; CARVALHO, M. P.; MELLO, L. M. M.; LIMA, R. C. Correlação linear e espacial entre a produtividade de forragem, a porosidade total e a densidade do solo de Pereira Barreto (SP). Revista Brasileira de Ciência do Solo, v.31, n.1, p.1233-1244, 2007. http://dx.doi.org/10.1590/S010006832007000600002.

MARCOLIN, C. D.; KLEIN, V. A. Determinação da densidade relativa do solo por uma função de pedotransferência para a densidade do solo máxima. Acta Scientiarum, v.33, n.2, p.349-354, 2011. http://dx.doi.org/10.4025/actasciagron.v33i2.6 120.

MARINHO, A. C. C. S.; PORTELA, J. C.; SILVA, E. F.; DIAS, N. S.; JÚNIOR, F. S. S.; SILVA, A. C.; SILVA, J. F. Organic matter and physicochemical attributes of a cambisol under different agricultural uses in a semi-arid region of Brazil. Australian Journal of Crop science, v.10, n.1, p.32-41, 2016.

http://www.cropj.com/portela_10_1_2016_32_ 41.pdf

MIOTTI, A. A.; COSTA, M.C.G.; FERREIRA, T.O.; ROMERO, R.E. Profundidade e atributos físicos do solo e seus impactos nas raízes de bananeiras Revista Brasileira de Fruticultura, v.35, n.2, p.536-545, 2013. http://dx.doi.org/10.1590/S010029452013000200024. 
MOME FILHO, E. A. Aplicação da penetrometria na quantificação da compactação do solo. 2012, 90 f. Dissertação (Mestrado - Curso de Ciências). Escola Superior de Agricultura "Luiz de Queiroz", Piracicaba.

REICHARDT, K.; TIMM, L. C. Solo, planta e atmosfera: Conceitos, processos e aplicações. 2. ed. Barueri: Manole, 2012. 500p.

ROMERO, E. M. Condutividade hidráulica, porosidade e resistência à penetração em Latossolos artificialmente compactados. 2007, 67 f. Dissertação (Mestrado - Curso de Engenharia Agrícola). Universidade Federal de Viçosa, Viçosa.

SILVA, S. G. C. Variação temporal da densidade do solo e do grau de compactação de um Latossolo Vermelho sob plantio direto escarificado. 2011, 67 f. Dissertação (Mestrado - Curso de Agronomia). Universidade de São Paulo, Piracicaba.

SILVEIRA, D. C.; MELO FILHO, J. F.; SACRAMENTO, J. A. A. S.; SILVEIRA, E. C. P. Relação umidade versus resistência à penetração para um Argissolo Amarelo distrocoeso no recôncavo da Bahia. Revista Brasileira de Ciência do Solo, v.34, n.3, p.659-667, 2010. http://dx.doi.org/10.1590/S010006832010000300007.

SOUZA, R. O. Caracterização etnopedológica em um cambissolo eutrófico em diferentes usos agropecuários na chapada do Apodi. 2014, 81 f. Dissertação (Mestrado - Curso de Agronomia). Universidade Federal Rural do Semiárido, Mossoró.

STONE, L. F.; GUIMARÃES, C. M.; MOREIRA, J. A. A. Compactação do solo na cultura do feijoeiro - 1: efeitos nas propriedades físico-hídricas do solo. Revista Brasileira de Engenharia Agrícola e Ambiental, Campina Grande, v.6, n.2, p.207-12, 2002. http://dx.doi.org/10.1590/S141543662002000200004

TEIXEIRA, P. C.; DONAGEMMA G. K.; WENCESLAU, A. F.; TEIXEIRA, G. Manual de Métodos de Análise de Solo. 3. ed. Rio de Janeiro: Embrapa Solos, 2017, 573 p.

TORMENA, C. A.; BARBOSA, M. C.; COSTA, A. C. S.; GONÇALVES, A. C. A. Densidade, porosidade e resistência à penetração em Latossolo cultivado sob diferentes sistemas de preparo do solo. Scientia Agricola, Piracicaba, v.59, n.4, p.795-801, $2002 . \quad$ http://dx.doi.org/10.1590/S010390162002000400026.

UNTERLEITNER, B. Avaliação das diferentes velocidades de rotação de agitadores horizontais, para análise granulométrica de alguns Latossolos. 2011, 39 f. Monografia (Especialização - Curso de Engenharia Agronômica), Universidade Federal Rural do Rio de Janeiro, Seropédica. 